\title{
Grounding line migration through the calving season at Jakobshavn Isbræ, Greenland, observed with terrestrial radar interferometry
}

\author{
Surui Xie ${ }^{1}$, Timothy H. Dixon ${ }^{1}$, Denis Voytenko ${ }^{2}$, Fanghui Deng ${ }^{1}$, and David M. Holland ${ }^{2,3}$ \\ ${ }^{1}$ School of Geosciences, University of South Florida, Tampa, FL, USA \\ ${ }^{2}$ Courant Institute of Mathematical Sciences, New York University, New York, NY, USA \\ ${ }^{3}$ Center for Global Sea Level Change, New York University, Abu Dhabi, UAE
}

Correspondence: Surui Xie (suruixie@mail.usf.edu)

Received: 10 October 2017 - Discussion started: 5 January 2018

Revised: 17 March 2018 - Accepted: 27 March 2018 - Published: 17 April 2018

\begin{abstract}
Ice velocity variations near the terminus of Jakobshavn Isbræ, Greenland, were observed with a terrestrial radar interferometer (TRI) during three summer campaigns in 2012, 2015, and 2016. We estimate a $\sim 1 \mathrm{~km}$ wide floating zone near the calving front in early summer of 2015 and 2016, where ice moves in phase with ocean tides. Digital elevation models (DEMs) generated by the TRI show that the glacier front here was much thinner (within $1 \mathrm{~km}$ of the glacier front, average ice surface is $\sim 100$ and $\sim 110 \mathrm{~m}$ above local sea level in 2015 and 2016, respectively) than ice upstream (average ice surface is $>150 \mathrm{~m}$ above local sea level at $2-3 \mathrm{~km}$ to the glacier front in 2015 and 2016). However, in late summer 2012, there is no evidence of a floating ice tongue in the TRI observations. Average ice surface elevation near the glacier front was also higher, $\sim 125 \mathrm{~m}$ above local sea level within $1 \mathrm{~km}$ of the glacier front. We hypothesize that during Jakobshavn Isbræ's recent calving seasons the ice front advances $\sim 3 \mathrm{~km}$ from winter to spring, forming a $>1 \mathrm{~km}$ long floating ice tongue. During the subsequent calving season in mid- and late summer, the glacier retreats by losing its floating portion through a sequence of calving events. By late summer, the entire glacier is likely grounded. In addition to ice velocity variation driven by tides, we also observed a velocity variation in the mélange and floating ice front that is non-parallel to long-term ice flow motion. This cross-flow-line signal is in phase with the first time derivative of tidal height and is likely associated with tidal currents or bed topography.
\end{abstract}

\section{Introduction}

Greenland's largest marine-terminating glacier, Jakobshavn Isbræ, has doubled in speed and retreated tens of kilometers in the last few decades (Joughin et al., 2004, 2008; Rignot and Kanagaratnam, 2006; Howat et al., 2011). This process has been attributed to several processes, including increased subsurface melting and iceberg calving triggered by relatively warm ocean water (Holland et al., 2008; Motyka et al., 2011; Enderlin and Howat, 2013; Myers and Ribergaard, 2013; Truffer and Motyka, 2016). In recent years, the glacier has maintained a relatively stable terminus position despite continued speedup, primarily due to the fact that the glacier is now embedded in the ice sheet, with large inflows of ice from the sides supplying ice to the main glacier channel, albeit with some thinning (Joughin et al., 2008). However, it is not clear if this configuration is stable, as Jakobshavn Isbræ has a retrograde bed (Clarke and Echelmeyer, 1996; Gogineni et al., 2014). Some numerical models suggest that glaciers with reverse bed slopes cannot maintain stable grounding lines, as bed topography favors ingress of warm fjord bottom water, accelerating melting at the ice-ocean interface (e.g., Vieli et al., 2001; Schoof, 2007).

In addition to the dramatic secular speedup and retreat, there are strong seasonal variations in both ice speed and front position at Jakobshavn Isbræ. These have an inverse correlation: ice accelerates through spring and summer but slows down in winter, while glacier front position retreats from spring to summer, reaching a minimum in late summer when ice speed is maximum (Joughin et al., 2008). This supports the hypothesis that loss of the buttressing ice tongue during the calving season contributes to Jakobshavn 
Isbræ's seasonal speedup. The rapid acceleration since 2000 may thus be the sequential result of losing its large floating ice tongue from 1998 to 2003 (Joughin et al., 2004, 2008), though Van Der Veen et al. (2011) suggested that progressive weakening of ice in the lateral shear margins is a more plausible explanation for the acceleration. By investigating interactions between the glacier and its pro-glacial ice mélange, Amundson et al. (2010) interpreted the seasonal advance and retreat of the glacier terminus as an effect of seasonally variable rheology in the ice mélange: stiffened mélange in winter suppresses major calving events, enabling the terminus to move forward; while in summer, a weaker mélange can no longer prevent major iceberg calving, and the terminus retreats. They used a force balance analysis to demonstrate that large-scale (full-glacier-thickness icebergs) calving events are not likely to occur when the ice front is well grounded. Based on this, they suggested that one of the necessary conditions for frequent full-glacier-thickness iceberg calving at Jakobshavn Isbræ is a floating or close-to-floating terminus in summer.

Currently, it is challenging to observe grounding line position directly when it lies near the calving front. However, this can be inferred from observations of ice motion (Heinert and Riedel, 2007; Rignot et al., 2011; Rosenau et al., 2013). For many marine-terminating glaciers, ice speed is affected by ocean tides (e.g., Makinson et al., 2012; Podrasky et al., 2014; Voytenko et al., 2015a). At Jakobshavn Isbræ, Podrasky et al. (2014) used GPS and theodolite data obtained in a 2-week campaign in middle to late August 2009 to study velocity response to ocean tidal forcing near the terminus of Jakobshavn Isbræ. After removal of a high background speed and perturbations caused by a single calving event, tidal forcing explained a significant fraction of the remaining signal. Based on the fast decay of tidal response upstream, they concluded that the terminus region is very nearly grounded during summer months. Rosenau et al. (2013) used photogrammetric time-lapse imagery to estimate groundling line migration and calving dynamics at Jakobshavn Isbræ. They found that the groundling line retreated $3.5 \mathrm{~km}$ from 2004 to 2010 , with an ephemeral floating tongue during the advance season.

In this study, we use ice velocity and elevation time series observed with terrestrial radar interferometry (TRI) to analyze groundling line position and tidally affected ice flow. Previous work (Peters et al., 2015; Voytenko et al., 2015a, b, c, 2017; Holland et al., 2016; Xie et al., 2016) has shown that TRI can overcome the limitations of GPS (low spatial resolution, difficult to deploy near the calving front), theodolite (low spatial resolution and precision), photogrammetry (low reliability in bad weather and at night), and satellite observations (low temporal resolution). Here we use TRI measurements obtained in three summer campaigns, but at different stages (early versus late summer) of the calving season, to investigate tidal response and the evolving glacier front through Jakobshavn Isbræ's calving season.
Table 1. TRI observation parameters.

\begin{tabular}{lllrr}
\hline Year & $\begin{array}{l}\text { Start } \\
\text { day }\end{array}$ & $\begin{array}{l}\text { End } \\
\text { day }\end{array}$ & $\begin{array}{r}\text { Scanned } \\
\operatorname{arc~}\left(^{\circ}\right)\end{array}$ & $\begin{array}{r}\text { Repeat } \\
\text { time* }^{*}(\min )\end{array}$ \\
\hline 2012 & 31 July & 12 August & 120 & 3 \\
2015 & 6 June & 10 June & 150 & 1.5 \\
2016 & 7 June & 20 June & 170 & 2 \\
\hline
\end{tabular}

* Time between two adjacent scans.

\section{Data acquisition}

We observed the terminus of Jakobshavn Isbræ in three summer campaigns in 2012, 2015, and 2016. Each campaign obtained a continuous record of velocity and elevation change over 4 to 13 days. The TRI instrument (GAMMA Portable Radar Interferometer) is a real-aperture radar operating at $\mathrm{Ku}$-band $(1.74 \mathrm{~cm}$ wavelength) and is sensitive to line-ofsight (LOS) displacements of $\sim 1 \mathrm{~mm}$ (Werner et al., 2008). It has one transmitting and two receiving antennas, which allows for high spatial and temporal resolution measurements of both displacement and topography. The antennas are rigidly attached to a rack structure, which sits on a motor that rotates around a fixed vertical axis. In 2012, the instrument was deployed on a tripod reinforced with sandbags, with the calving front $\sim 3-6 \mathrm{~km}$ away. In 2015 and 2016, the instrument was mounted on a metal pedestal connected to bedrock with $10 \mathrm{~cm}$ bolts and protected by a radome to eliminate disturbance from wind and rain, with the calving front $\sim 2-5 \mathrm{~km}$ away. In all three campaigns, the radar scanned to a maximum distance of $16.9 \mathrm{~km}$, generating images with both phase and intensity information. The resolution of the range measurement is $\sim 1 \mathrm{~m}$. The azimuth resolution varies linearly with distance and varies as the arc length $l=D \cdot A$, where $D$ is the distance to the radar and $A$ is the azimuth angle step in radians, ultimately related to radar wavelength and antenna size. In all three campaigns, the azimuth angle steps were $0.2^{\circ}$, resulting in an azimuth resolution of $7 \mathrm{~m}$ at $2 \mathrm{~km}$ distance, $14 \mathrm{~m}$ at $4 \mathrm{~km}$, etc. Other parameters in these measurements are listed in Table 1. Figure 1 shows the spatial coverage of measurements in each campaign.

\section{Data analysis}

\subsection{TRI data processing}

TRI data were processed following Voytenko et al. (2015b): (1) slant range complex images were multi-looked to reduce noise; (2) interferograms were generated between adjacent scans; and (3) a stationary point on rock was chosen as a reference for phase unwrapping. Unwrapped phases were then converted to LOS velocities. We define LOS velocity as positive when ice moves towards the radar and negative when ice moves away from the radar. All results were resampled into 


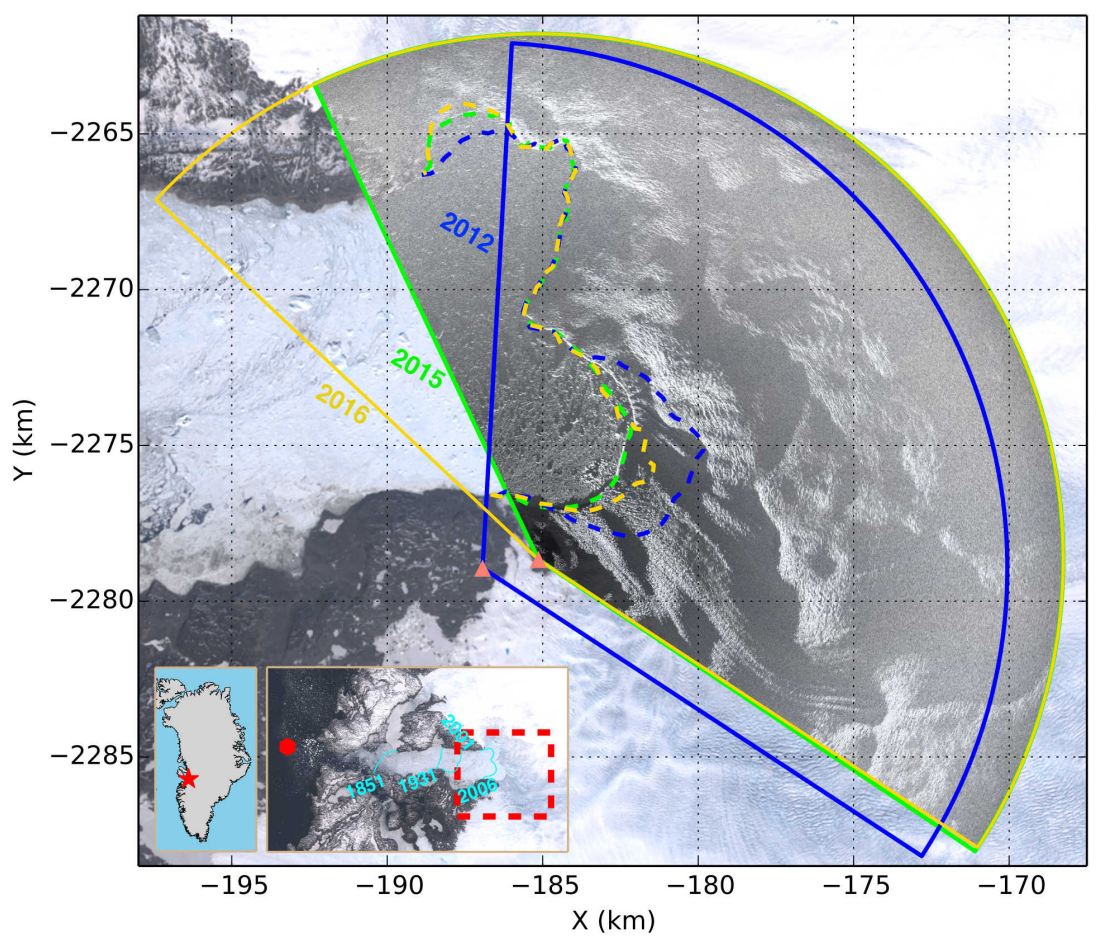

Figure 1. TRI scan areas in 2012 (blue), 2015 (green), and 2016 (yellow). An intensity image of radar backscatter from the 2015 campaign (acquired 9 June 2015) is overlain on a Landsat-8 image (acquired 4 June 2015). Dashed lines indicate glacier front locations derived from satellite images: Landsat-7 on 6 August for 2012; Landsat-8 on 4 June for 2015; and Landsat-8 on 13 June for 2016. Triangles in salmon color show locations of the radar. Dashed red box in the insert outlines the area shown in the main figure. Cyan lines in the insert show the calving front positions in different years, courtesy of NASA Earth Observatory (https://earthobservatory.nasa.gov/Features/Greenland/ greenland3.php). Red hexagon in the insert marks the mooring location where tidal height was recorded in 2015. Red star in the insert shows the location of the study area in Greenland. Coordinates are in polar stereographic projection, corresponding to EPSG:3413.

$10 \mathrm{~m} \times 10 \mathrm{~m}$ pixel spacing maps unless otherwise specified, with a bicubic spline interpolation algorithm. To georeference the TRI results, we used a Landsat-7/8 image acquired during (if not possible, then with a $<2$-day time difference) the observation period as a reference. By fixing the radar location and horizontally rotating the intensity image, a rotation angle was estimated based on the best match of distinct surface features (e.g., coast line, ice cliff, icebergs); thus TRIderived results were georeferenced into the earth reference system. In this study, we use the polar stereographic projection to minimize distortion. Notice that the TRI instrument measures LOS intensity and phase information. Converting LOS data into $x-y$ grid coordinates induces some distortions due to topography, especially in the mélange close to the radar, where the height differences are largest. The radar location in 2012 was $\sim 280 \mathrm{~m}$ above local sea level, and in 2015/2016 $200 \mathrm{~m}$ above local sea level. A simple calculation based on geometry shows that distortion due to topography is $<15 \mathrm{~m}$. There are two other error sources in georeferencing TRI data: (1) radar position error (it was measured with a single-frequency GPS, with location error estimated at less than $10 \mathrm{~m}$ ) and (2) rotation error in matching TRI and Landsat images. By comparing georeferenced TRI images with different Landsat-7/8 images, we found no visible mismatch larger than four pixel widths of the satellite images. We thus assess that the coordinate error in georeferenced TRI results is $<60 \mathrm{~m}$, i.e., smaller than four pixels (typically $<2$ pixels) of Landsat-7/8 panchromatic images. Moreover, because the radar was deployed on a fixed point in each campaign, and we used the same radar coordinates and rotation angle in georeferencing for each campaign, the error due to georeferencing will not affect our time series analysis. Other errors in TRI data, such as phase variations associated with variable atmospheric water vapor between adjacent scans, are difficult to model but should not be significant in the near field given the 1.5-3 min repeat time. To minimize water vapor effects, we only analyzed data within $10 \mathrm{~km}$ of the radar unless otherwise specified.

TRI data obtained in 2015 have been previously discussed in Xie et al. (2016). The same data are used here, but we added $17 \mathrm{~h}$ of additional data obtained before the period analyzed by Xie et al. (2016). The additional data were acquired when the instrument was in an experimental mode: rather than $150^{\circ}$ of scan, the scanned arc was sometimes set to different values, and the repeat time was sometimes 1 or $2 \mathrm{~min}$ rather than $1.5 \mathrm{~min}$. Otherwise, the additional data have the 
same quality as subsequent acquisitions. We processed the additional data with the same standards and converted them into the same reference frame as the remaining 2015 data.

Except for several rapid changes in velocity caused by calving events, the processed results from 2015 and 2016 have good continuity. However, velocities from 2012 have some significant offsets (Fig. S1a in the Supplement). Most of these offsets reflect phase unwrapping errors, reflecting incorrect integer multiples of microwave cycles applied during the phase unwrapping process. The repeat time in 2012 ( $3 \mathrm{~min}$ ) was longer than the other two years, and ice motion relative to adjacent areas in the radar LOS during that interval could exceed one radar wavelength. We fixed these phase offsets in three steps: (1) estimate the velocity time series at a single point on the ice (with integer multiples of microwave cycles corrected); (2) use this kinematic point as the reference point for phase unwrapping to get relative velocities for all other mapped points; and (3) add the velocity model from step 1 to the relative velocities. We compared this new velocity map with velocities estimated by feature tracking (done with Open Source Computer Vision Library: https://opencv.org/; uncertainty is typically $<1 \mathrm{~m} \mathrm{~d}^{-1}$ for a pair of images separated by 1 day), which is independent of interferometry and does not require phase connection. The phase jumps are greatly reduced, and we believe the resulting velocity time series are an accurate indicator of ice motion. Details are given in Sect. S1 and Figs. S1-S5.

\subsection{Tidally driven ice motion analysis}

The glacier directly interacts with the ocean at the calving front. By changing back pressure on this front, ocean tides are known to influence the behavior of some marineterminating glaciers (Walters, 1989; Anandakrishnan and Alley, 1997; Podrasky et al., 2014). Besides back pressure, a full-Stokes nonlinear viscoelastic model (Rosier and Gudmundsson, 2016) suggests that, when there is a floating ice tongue, tidal flexural stress can also be an important forcing for marine-terminating glaciers. In addition, tidal variation can influence basal friction at the ice-bed interface, thus changing the sliding rate of the glacier (e.g., Walker et al., 2013; Voytenko et al., 2015a).

For all three campaigns, velocities near the terminus show significant semi-diurnal variation and perhaps a small diurnal signal. Figure 2 shows the power spectral density (PSD) analysis for selected data in 2016. PSDs for 2012 and 2015 are shown in Sect. S2, Figs. S6 and S7. Previous studies indicate that, apart from calving events, short-term ice velocity variations at Jakobshavn Isbræ are well described with simple tidal response models (e.g., Rosenau et al., 2013; Podrasky et al., 2014). Diurnal variation caused by surface melting may also contribute to velocity variation. This has been observed at both Jakobshavn Isbræ (Podrasky et al., 2012) and Helheim Glacier (Davis et al., 2014). Due to the short time span of our data, it is not possible to recover the full temporal spectrum of ice velocity variations. Instead, we focus on the largest spectral components of the velocity field.

There was no tide record in the fjord near the terminus during our campaigns. Podrasky et al. (2014) analyzed a 14-day tide record in the fjord within $5 \mathrm{~km}$ of the calving front obtained in August 2009 and compared it with a longer record from Ilulissat. The two datasets show close agreement, with no measurable delay in time, and a maximum difference in stage $<10 \mathrm{~cm}$. Thus they used the longer record of tides at Ilulissat to analyze the tidal response of the glacier. We also used analyzed tidal constituents from the long-term record at Ilulissat to predict tides in the fjord during our campaigns. Richter et al. (2011) applied harmonic tidal analysis to 5 years of long-term sea-level records at Ilulissat and estimated that the largest three tidal constituents are K1, M2, and S2, with amplitudes of $0.331,0.671$, and $0.273 \mathrm{~m}$, respectively. These three constituents account for $>95 \%$ of all the analyzed tidal constituents. Figure S8 shows the predicted tide and tidal rate (defined as the first time derivative of tidal height) during the 2015 campaign, when we had a mooring deployed at the mouth of the fjord (red hexagon in Fig. 1) that recorded tidal height. There are only small differences between measured tide or tidal rate with predictions using the three largest constituents. In the following analysis, we focused on ice velocities with the same frequencies as the $\mathrm{K} 1, \mathrm{M} 2$, and S2 tide constituents. Other components of tidal motion with similar frequencies will be aligned into these three constituents. For example, diurnal variation caused by surface melting with a period of $\sim 1 \mathrm{~d}$, if it exists, will not be separable from K1 with a period of $1.0027 \mathrm{~d}$.

Many tidal response models analyze the response of ice position to tidal height variation (e.g., Davis et al., 2014; Podrasky et al., 2014). However, our TRI measurements are only sensitive to LOS displacement. The corresponding velocity derived by interferometry is the first time derivative of LOS displacement. Velocity can be converted to position by integration; however, due to data gaps and the nonlinear behavior of the velocity time series, integration of velocity time series may introduce artifacts. Therefore, we used ice velocity instead of position and analyzed the response of ice velocity to tidal rate. The amplitude of variation is magnified by frequency (signals with higher frequencies will have larger ranges of first time derivative; see Sect. S3), but the phase difference is unchanged by differentiation.

Before the tidal response analysis, we used the modified $Z$-score method (Iglewicz and Hoaglin, 1993; also see Sect. S1) to remove outliers. We note that TRI-observed ice motion in the mélange is very sensitive to small calving events, while ice on the glacier is less affected. Due to frequent calving events in the 2012 data, we were not able to accurately model the full time series. Instead, we used data obtained from 6 to 10 August when there was only one small calving event (see Fig. S1) for the following analysis. For the 2015 data, there were many small calving events and a large one at the end (Xie et al., 2016), resulting in a noisy time se- 

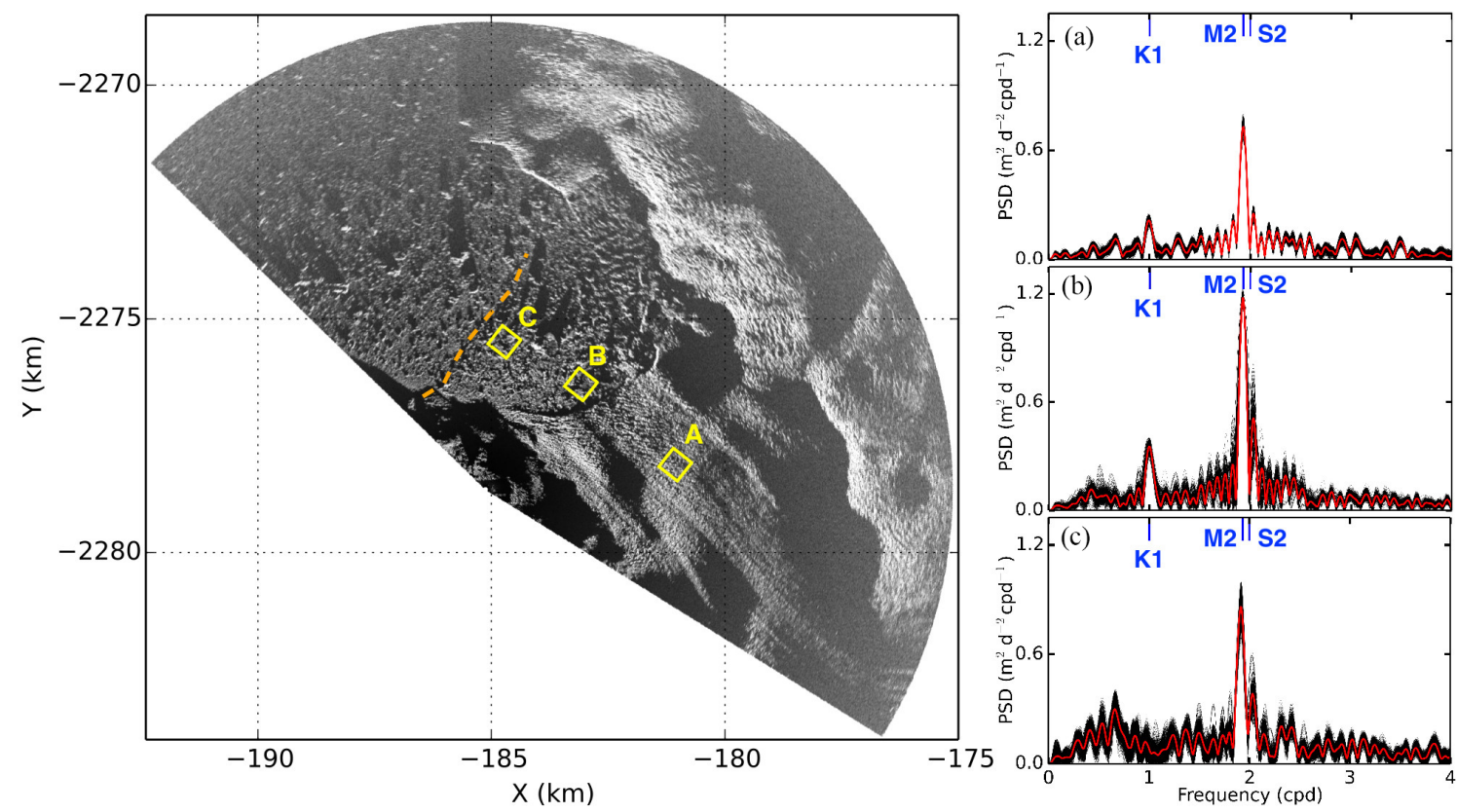

Figure 2. Stacked power spectral density (PSD) estimates of the LOS velocity time series for selected areas in 2016 . Three $0.5 \mathrm{~km} \times 0.5 \mathrm{~km}$ boxes $(\mathbf{a}, \mathbf{b}$, and $\mathbf{c})$ mark the selected areas. PSD plots are normalized, and each black line represents 1 pixel $(10 \mathrm{~m} \times 10 \mathrm{~m})$ in the corresponding box. Red line shows mean value. Blue lines mark frequencies of K1, M2, and S2 tide constituents. On map to the left, dashed orange line shows a significant step change of height in the mélange observed in 2016 (see also Fig. 3a).

ries for the mélange. We therefore omitted the 2015 mélange from further analysis. For 2016, a step change in ice elevation (dashed orange line in Fig. 2) was observed, separating the mélange into two distinct parts. Downstream from the step change, ice motion is very noisy and difficult to analyze for periodic signals. Upstream from that, ice velocity variation is similar to the glacier. Therefore, we did not do tidal response analysis for the ice mélange downstream from the step change in 2016. Movies S1, S2, and S3 show all major calving or calving-like (collapse of tightly packed mélange) events observed during the three campaigns, and corresponding changes in the mélange.

For both 2012 and 2015 campaigns, $\sim 4$ days of data were analyzed, and a second-order polynomial was used to detrend the time series. For the 2016 campaign, $\sim 13$ days of data were analyzed. This time series shows significant responses to a few calving-like collapse events (Fig. 3). We used a function composed of a second-order polynomial +3 pairs of sines and cosines to estimate the response to calving(-like) events and then removed the polynomial. The function is

$$
\begin{aligned}
V_{i} & =a_{j}+b_{j} t+c_{j} t_{i}^{2}+\sum_{k=1}^{3}\left[d_{k} \sin \left(2 \pi f_{k} t_{i}\right)\right. \\
& \left.+e_{k} \cos \left(2 \pi f_{k} t_{i}\right)\right],
\end{aligned}
$$

where $V_{i}$ is the observed LOS velocity at time $t_{i}$, and $a_{j}, b_{j}$, and $c_{j}$ are coefficients of second-order polynomial for the $j$ th period, where periods are separated by large calving(-like) events. To better estimate the second-order polynomial, periods with data spanning shorter than 1 day are not used. $d_{k}$ and $e_{k}$ are coefficients of the $k$ th periodic component, with frequency $f_{k}$ among those of $\mathrm{K} 1, \mathrm{M} 2$, and $\mathrm{S} 2$ tidal constituents. Response to calving events and tidal constituents with periods $>2$ days is largely eliminated with this procedure. Figure 3 gives an example of the observed and detrended time series. Note that data in 2016 span longer times than 2012 and 2015. To save computational time, we converted TRI images into pixel sizes of $30 \mathrm{~m} \times 30 \mathrm{~m}$ for a map-wide analysis.

Detrended time series were passed through a median filter to reduce noise. The kernel size is 3,5 , and 5 for data in 2012, 2015, and 2016, equal to a 9, 7.5, and $10 \mathrm{~min}$ time window, respectively. All time series were then analyzed using the method of Davis et al. (2014), which estimates the amplitudes and phases of the three periodic components with the same frequencies as the K1, M2, and S2 tidal constituents. This method allows us to distinguish components with close frequencies (in our case, M2 and S2). We also used a least squares fit to an equation with three frequencies of sines and cosines as an alternative method. The two methods fit the time series equally well, with differences that are insignificant compared to noise. Note that we assume constant tidal response for each campaign, whereas in reality tidal response can have temporal variation due to calving and other processes. However, previous work at Jakobshavn Isbræ (Podrasky et al., 2014) and Helheim Glacier (de Juan et al., 

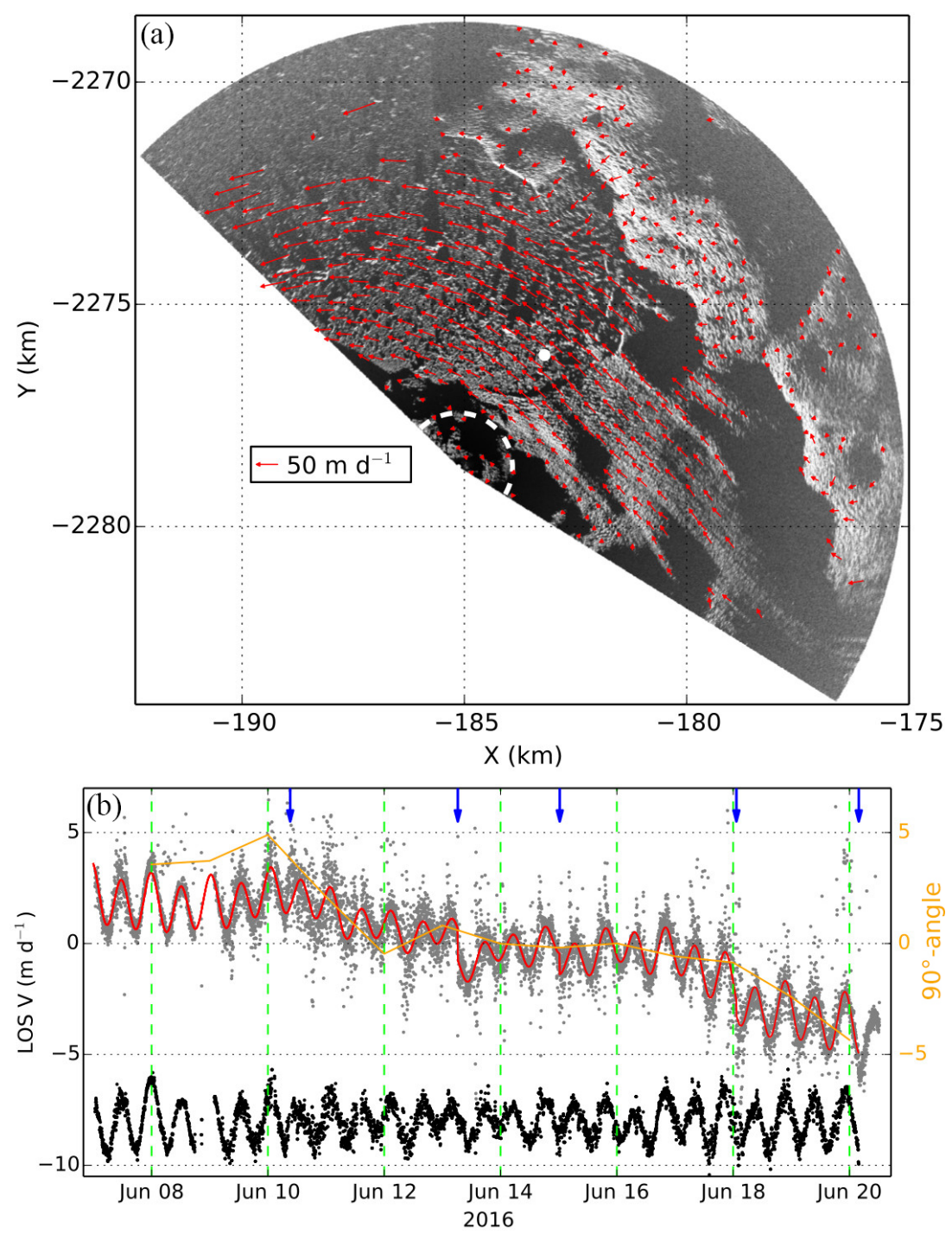

Figure 3. (a) Ice velocity estimated by feature tracking using a pair of TRI intensity images separated by 1 day in the 2016 campaign. Dashed white line outlines the area with (nearly) stationary points used to define uncertainty of velocity estimate; the rms of velocity estimates (without detrending) by feature tracking within the dashed outline is $<1 \mathrm{~m} \mathrm{~d}^{-1}$. (b) TRI-observed LOS velocity time series for a single point, marked by white dot in (a). Grey dots show velocities derived from unwrapped phases, red curve shows the model used to remove perturbations caused by calving events, and black dots show detrended time series offset by $-8 \mathrm{~m} \mathrm{~d}^{-1}$. Blue arrows mark large calving or calving-like collapse events. Orange line shows changes of angle between LOS and 2-D ice velocity direction by feature tracking. The LOS velocity variation for a period longer than $1 \mathrm{~d}$ is mostly due to changes in background velocity direction.

2010) shows that this variation will not significantly change the phase of tidal response during a period of few weeks.

Figure $4 \mathrm{~b}, \mathrm{~d}$, and $\mathrm{f}$ show maps of phase lag (converted to time in hours) from tidal rate to TRI-observed LOS velocity at the M2 tidal frequency, along with a velocity profile for each campaign. Note that, due to the phase character of periodic signals, dark red on the map represents phase values that are close to dark blue. For example, $12.42 \mathrm{~h}$ (period of M2) "equals" 0 . Note also that the phase lag maps only show pixels with signal-to-noise ratio $(\mathrm{SNR})>1.5$, where we define
SNR as

$\mathrm{SNR}=\frac{\sigma_{\text {signal }}^{2}}{\sigma_{\text {noise }}^{2}}$.

We use the root mean square (rms) of the detrended velocity time series to represent $\sigma_{\text {signal }}$, and $\mathrm{rms}$ of the residuals to represent $\sigma_{\text {noise. }}$. We use the M2 tidal signal to illustrate tidal responses since this is the largest tidal constituent. Phase lag maps for K1 and S2 are shown in Fig. S9, with patterns that are similar to M2. 

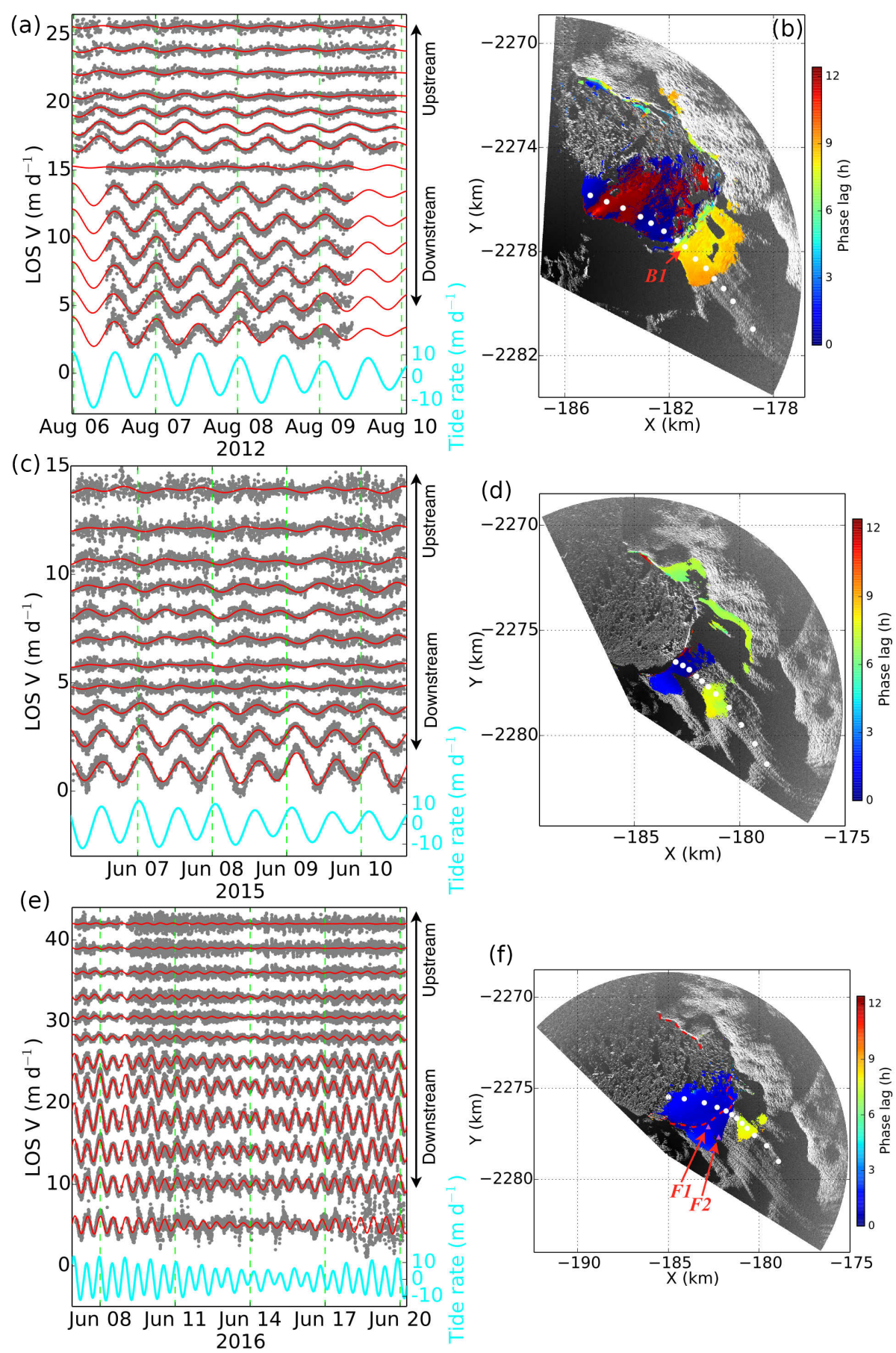

Figure 4. Phase lag map and velocity time series for a profile in each campaign. Grey dots (a, c, e) show detrended LOS velocity time series for a profile along the ice flow line, marked by white dots on the map to the right. Red curve shows best model fit. LOS velocities are offset for clarity. Cyan curve shows tidal rate. Phase lag map (b, d, f) shows M2 frequency signal. Areas where SNR $<1.5$ are omitted. Phase lags are converted to times (in hours). In (f), dashed red line shows TRI-derived location of glacier front on 13 June 2016. B1, F1, and F2 mark selected points showing velocity time series in Fig. 6. Note that the amplitude of detrended LOS velocity depends on a number of factors, including tidal response, ice flow direction relative to radar LOS, distance up-glacier, whether the scanned area is glacier or mélange, and (within the mélange) whether the imaged pixel is close to or far from the calving front. 


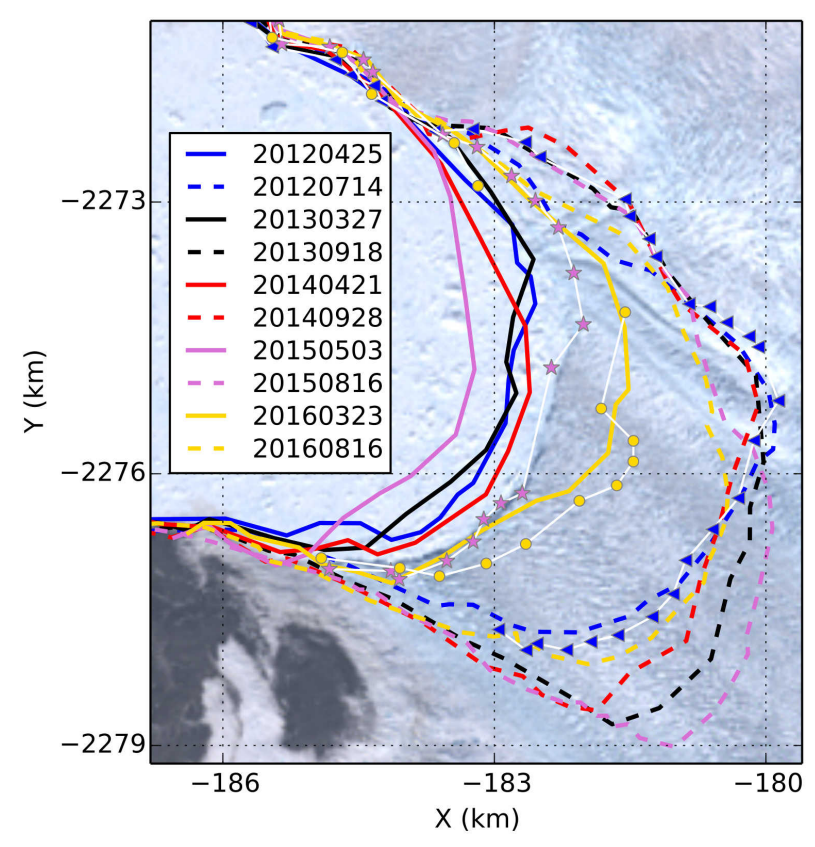

Figure 5. Annual maximum and minimum extents of Jakobshavn Isbræ's calving front from 2012 to 2016. Solid lines show the glacier front when glacier extent is maximum, and dashed lines when glacier extent is minimum. Glacier front locations are derived from available Landsat-7/8 and Sentinel-2 images in USGS archive. Legends are dates of image acquisition. Lines with triangles, stars, and circles show glacier front locations during TRI campaigns in 2012 (6 August), 2015 (9 June), and 2016 (13 June), respectively. Background for this figure is a Landsat-8 image acquired on 4 June 2015.

Figure 4 shows two types of phase lag patterns. For 2012, LOS velocity of ice in the mélange has $\sim 0$ phase lag to tidal rate, whereas the phase lag increases sharply at the calving face, to $\sim 8.5 \mathrm{~h}$ on the glacier front. For both 2015 and 2016, there is a narrow zone at the glacier front that is in phase with the tidal rate, with phase lag close to 0 . Upstream from that, phase lag increases to $\sim 8 \mathrm{~h}$.

\section{Discussion}

\subsection{Grounding line variation in a calving season}

One hypothesis concerning the annual cycle of advance and retreat of Jakobshavn Isbræ is that a floating tongue grows in winter and disappears in late summer (Joughin et al., 2008; Amundson et al., 2010). However, there are no direct observations through a full calving season. We addressed this by assuming consistent behavior over the 5-year observation period and considering our data to be a representative sample of early and late melt season behavior. This assumption is based on the relatively regular seasonal variations in calving front positions over the observation period from satellite images (Fig. 5) and the good inverse correlation between seasonally varying speed and length of ice tongue (Joughin et al., 2008, 2014).

Rosenau et al. (2013) looked at the cross-correlation coefficient between tidal height and the vertical component of ice trajectory to estimate grounding line migration. This approach assumes that the only force that drives vertical ice motion is tide rise and fall. From an analysis of optical images, they found no evidence of floatation in mid-July 2007 ( $\sim 6$-day duration), a $\sim 500 \mathrm{~m}$ wide floating zone from 8 to 9 August 2004 ( $\sim 1$-day duration), and an even wider floating zone from late spring to early summer 2010 ( 29-day duration). Podrasky et al. (2014) applied a tidal admittance model to analyze both horizontal and vertical responses to tidal forcing at Jakobshavn Isbræ. They found rapid decay of admittance at the glacier front, corresponding to small $(\sim 2$ and $\sim 0.7 \mathrm{~km}$ for horizontal and vertical, respectively) $e$-folding lengths (the distance over which the amplitude decreases by a factor of $e$ ), concluding that the glacier front was very nearly grounded in late August 2009.

TRI-derived LOS velocities reflect several forcings. Surface meltwater-induced velocity variation is a quasi-diurnal signal. Podrasky et al. (2012) detected an amplitude of up to $0.1 \mathrm{~m} \mathrm{~d}^{-1}$ diurnal signal $20-50 \mathrm{~km}$ upstream from the terminus of Jakobshavn Isbræ. The timing of the diurnal maxima was $\sim 6 \mathrm{~h}$ after local noon, consistent with surface melting. Within $4 \mathrm{~km}$ of the glacier front, Podrasky et al. (2014) found diurnal variations that are $0.5-1$ times the amplitude of tidally forced variations, with a maxima $10.9-11.7 \mathrm{~h}$ after local noon. At Helheim Glacier, Davis et al. (2014) identified a signal with peak-to-peak variation of $\sim 0.7 \mathrm{~m} \mathrm{~d}^{-1}$ in glacier flow speed at a site close to the terminus, likely associated with changes in bed lubrication due to surface melting. While surface meltwater can cause a diurnal component in ice velocity, it should have no direct influence on semidiurnal signals, which are the dominant signals observed in all three of our campaigns. Supraglacial lake drainage events could be another possible forcing process, though they were not observed near the terminus during our campaigns. Upstream from the terminus, supraglacial lake drainage events occur but are sporadic. Podrasky et al. (2012) observed at most three supraglacial lake drainage events near the terminus during three summers from 2006 to 2008. If such events occurred during our data collection periods, the responses are likely to have been eliminated by the detrending process.

The LOS velocity variation contains two components of ice motion: (1) vertical motion and (2) horizontal motion. For all three campaigns, the radar was always located higher than the ice surface in the mélange and the first $\sim 3 \mathrm{~km}$ of the glacier. In this case, the TRI-observed LOS velocity component is

$V_{\text {los }}=\frac{1}{\sqrt{\left(\frac{L}{H_{0}-h}\right)^{2}+1}} \frac{\mathrm{d} h}{\mathrm{~d} t}$, 
where $L$ is the horizontal distance between the radar and target, $H_{0}$ is the mean height different between the radar and target, $h$ is the vertical movement relative to $H_{0}$, and $\frac{\mathrm{d} h}{\mathrm{~d} t}$ is the vertical component of ice velocity (see geometry in Fig. S10). We assume that, for floating ice, $\frac{\mathrm{d} h}{\mathrm{~d} t}$ is correlated with the tidal rate. Hence $\frac{\mathrm{d} h}{\mathrm{~d} t} \approx$ tidal rate in the mélange, and less than that for the glacier, but it can be close if ice near the glacier front is very weak, similar to what Voytenko et al. (2015a) found at the terminus of Helheim Glacier. For grounded ice, $\frac{\mathrm{d} h}{\mathrm{~d} t}$ variation should have a much smaller amplitude than tidal rate variation. Horizontally, for all three campaigns, ice on almost the entire glacier moves towards the radar (LOS velocity is positive; see Figs. S3, S4, and S5). Previous studies suggest that several mechanisms are acting simultaneously, and there is no single defined phase relation between tide variation and ice speed (e.g., Thomas, 2007; Aðalgeirsdóttir et al., 2008; Davis et al., 2014; Podrasky et al., 2014). However, at the terminus of Jakobshavn Isbræ, Podrasky et al. (2014) found that glacier speed and tidal height are anti-correlated. This likely reflects variation of back-pressure forcing associated with tide rise and fall.

We have not attempted to derive a comprehensive model for ice velocity variation caused by changes of back pressure or other factors. Instead, we adopt the admittance parameters estimated by Podrasky et al. (2014) to assess a near-upper bound of along-flow-line velocity variation. Using theodolite and GPS observations near the ice front, Podrasky et al. (2014) estimated horizontal and vertical tidal admittances of $<0.12$ and $<0.15$, respectively. In terms of phase, tideinduced vertical motion is in phase with the ocean tide, while horizontal velocity is anti-correlated with tidal height; i.e., horizontal velocity maxima are concurrent with the inflection points of tidal rate. By assuming the glacier was under the same conditions as the time when Podrasky et al. (2014) did their measurements, we predict ice velocities near the glacier front. In Fig. 6a, F1 and F2 correspond to the two points marked with purple triangles in Fig. 4f. For each point, two components of ice velocity were predicted and projected onto the LOS direction to the radar: (1) vertical velocity by using tidal admittance of 0.15 , and time lag of 0 to tidal rate, shown by solid black curve, and (2) horizontal velocity by using tidal admittance of 0.12 , and anti-correlated with tidal height, shown by the dashed black curve. The red curve shows the sum of these two components. Podrasky et al. (2014) inferred that the glacier front was very nearly grounded during their observation period, and both horizontal and vertical tidal admittances dropped dramatically upstream. While we use the upper bound of the tidal admittance by Podrasky et al. (2014), the amplitudes of our predicted velocities are almost the maxima for grounded ice. However, as shown in Fig. 6a, predicted tide-induced vertical velocities have far smaller magnitude than our TRI-derived velocities - the horizontal component is larger but is negatively correlated with TRI observations. Therefore, we reject the hy-
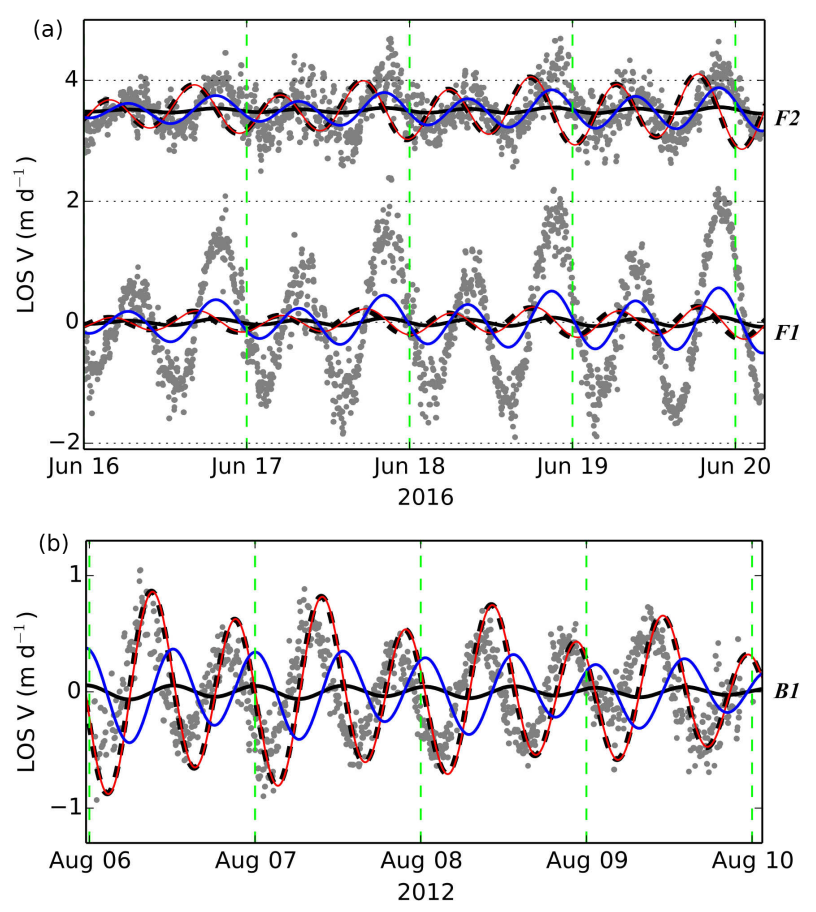

Figure 6. (a) Detrended LOS velocities of points located in the lowphase-lag zone in 2016. F1 and F2 are the two points marked with purple triangles in Fig. 4f; F2 (upstream one) has been offset by $3.5 \mathrm{~m} \mathrm{~d}^{-1}$ for clarity. Grey dots are observed time series. Solid black curve shows vertical response to tide variations, using admittance of 0.15 (Podrasky et al., 2014) projected onto the LOS direction. Dashed black curve is horizontal response by using admittance of 0.12 , projected onto the LOS direction. Red curve shows the sum of solid and dashed black curves; its Pearson correlation coefficient with observed time series is -0.13 and -0.19 for F1 and F2, respectively. Blue curve shows predicted LOS velocity by assuming ice is free-floating; its Pearson correlation coefficient with observed time series is 0.82 and 0.69 for F1 and F2, respectively. Note that $\sim 4$ days of data are used in this figure for clarity. (b) LOS velocities of a point immediately adjacent to the glacier front in 2012 (B1 in Fig. 4b); colors and curves represent the same parameters as in (a). The Pearson correlation coefficient with observed time series is 0.65 for the red curve (grounded or nearly grounded assumption, the same as Podrasky et al., 2014) and -0.56 for the blue curve (free-floating assumption).

pothesis that ice near the glacier front in early summer 2016 was nearly grounded as during the observation period of Podrasky et al. (2014) in late summer. For comparison, we also plot predicted LOS velocities by assuming ice was in a freeflotation state, shown in blue. This is in phase with the TRI derived velocities, although the magnitude does not fully explain the larger signals observed by TRI. Possible reasons are discussed below.

Ice located in the low-phase-lag zone (dark red or blue in Fig. 4d) in 2015 yields similar results. For ice further upstream in 2015 and 2016, and almost the entire glacier front of 2012, we cannot reject the possibility of a near-grounded 
basal condition, because the admittances by Podrasky et al. (2014) can then produce LOS velocities that are sufficiently large and correlated with TRI observations. Figure $6 \mathrm{~b}$ shows predicted (red curve) and observed (grey dots) velocity of a surface point (B1 in Fig. 4b) that is immediately adjacent to the glacier front during our 2012 campaign. They have similar amplitude and phase, though the maxima of TRI-observed velocity are not exactly concurrent with the inflection points of tidal rate. Instead, they are slightly earlier $(\sim 0.5 \mathrm{~h})$ than the inflection points. We presume that ice in the high-phaselag zone in Fig. 4 is either grounded or nearly grounded.

Based on this analysis, we hypothesize that during early summer 2015 and 2016 there was a narrow zone of floating ice near the glacier front, which is at least the width of the low-phase-lag zone $(\sim 1 \mathrm{~km})$. However, we are unable to determine if ice more than $1 \mathrm{~km}$ from the glacier front is grounded or not. The annual maximum and minimum extents of the ice front (solid/dashed lines in Fig. 5) support this hypothesis: the low-phase-lag zone on the glacier during both the 2015 and 2016 observations coincides with the transition zone between maximum and minimum glacier front. In contrast, for the 2012 data, the glacier front was close to the annual minimum. Additional evidence to support this hypothesis comes from the ice surface elevation map. Figure 7 shows the median average DEM from estimates of a 1-day TRI measurements for each campaign. In 2012, near the centerline of the main trunk, surface ice elevation increases dramatically near the glacier front, to $>120 \mathrm{~m}$ in $<1 \mathrm{~km}$ distance from the glacier front. In contrast, in 2015 and 2016, ice elevation increases more slowly, with a $\sim 1 \mathrm{~km}$ wide zone that is $<110 \mathrm{~m}$ higher than local sea level. In this low-elevation zone, overall buoyancy could make conditions favorable for a floating glacier front during early summer (2015 and 2016 data).

During the time span of our TRI campaigns, the glacier front maintained a relatively constant position, with $\sim 3 \mathrm{~km}$ ice advance and retreat per year. Time series of satellite images also suggest that in late summer to early autumn the glacier front usually stabilizes near the minimum position for a few weeks before a steady advance. Using the TRI campaign in 2012 as a proxy for late-summer conditions, and campaigns in 2015 and 2016 as proxies for early-summer conditions, we infer that from 2012 to 2016 Jakobshavn Isbræ had a floating tongue in the early stage of the calving season. Undercutting and tidal flexure then weakened the floating ice, leading to large calving events in subsequent months. During the calving season, calved ice surpassed ice flow into the terminus zone, causing the glacier front to retreat. In late stages of the calving season, the glacier had lost the majority of its floating tongue, and the ice front became grounded or nearly grounded.

\subsection{Other sources of forcing}

Figure 6a shows that, even when assuming ice is free-floating near the glacier front, LOS velocity variation generated by tide rise and fall is insufficient to explain the observed velocity time series. Ice velocity variation caused by surface melting, if in phase with tidal rate, can increase the overall velocity variation. In this study, we did not separate the quasidiurnal signal associated with surface melting from similar tidal components. However, there is some evidence of such a signal. As shown in the normalized PSD in Fig. 2c, the diurnal constituent is less obvious than in Fig. $2 a$ and b: assuming speed maxima caused by surface melting lags local noon by $6 \mathrm{~h}$, it will be in phase with the $\mathrm{K} 1$ ocean tide rate. Due to the geometry difference, TRI-observed LOS diurnal tidal signal will be superimposed on a negative (box C) or positive (box A and B) diurnal signal associated with surface melting, decreasing or enhancing the observed signal. Thus the diurnal constituent in Fig. $2 \mathrm{c}$ is smaller than the other two areas. However, surface melting should not make a significant contribution to semi-diurnal signals, as it is a diurnal phenomena. In addition, most sources of forcing would induce longitudinal velocity variations, and their signals should attenuate significantly near the glacier front due to the LOS geometry. The large additional variation shown in Fig. 6a has a significant component that is not parallel to long-term ice flow motion, i.e., in the cross-flow-line direction; thus it cannot be mainly caused by surface melting. We therefore studied points moving in a near-perpendicular direction to LOS, where along-flow-line motion (e.g., velocity variation due to surface melting) is likely to be negligible in the TRI data. The 2016 data are appropriate for this study.

We focused on three points in the mélange (Fig. 8a). The velocity estimates from both interferometry and feature tracking suggest that their along-flow line velocities are almost perpendicular to the radar LOS direction (within \pm 5 of $90^{\circ}$ ). Any longitudinal variation would be trivial when projected onto the LOS direction. Figure 8b shows that the LOS velocity variation caused by up-and-down ice motion that is directly related to tides can only explain about half of the observed signal. The extra signal has a strong correlation with tidal rate, with an amplitude of $\sim 1 \mathrm{~m} \mathrm{~d}^{-1}(\sim 0.1 \mathrm{~m}$ in displacement). This phase relation suggests that either bed topography or tidal currents are responsible for the signal that is non-parallel to long-term ice flow motion. Bed topography is not likely to be the main contributor, as it is more likely to affect glacier motion rather than mélange motion, unless mélange ice is strongly attached to the glacier. There is no ocean current record during our campaigns near the glacier front, and available models for the ice fjord are too coarse. However, as Doake et al. (2002) have discussed, the usually accepted drag coefficient between ice and water is not likely to create enough force to drive ice motion to a sufficient magnitude. To fully explain the periodic non-parallel signal, we need to either assume a very rough surface for ice below the 

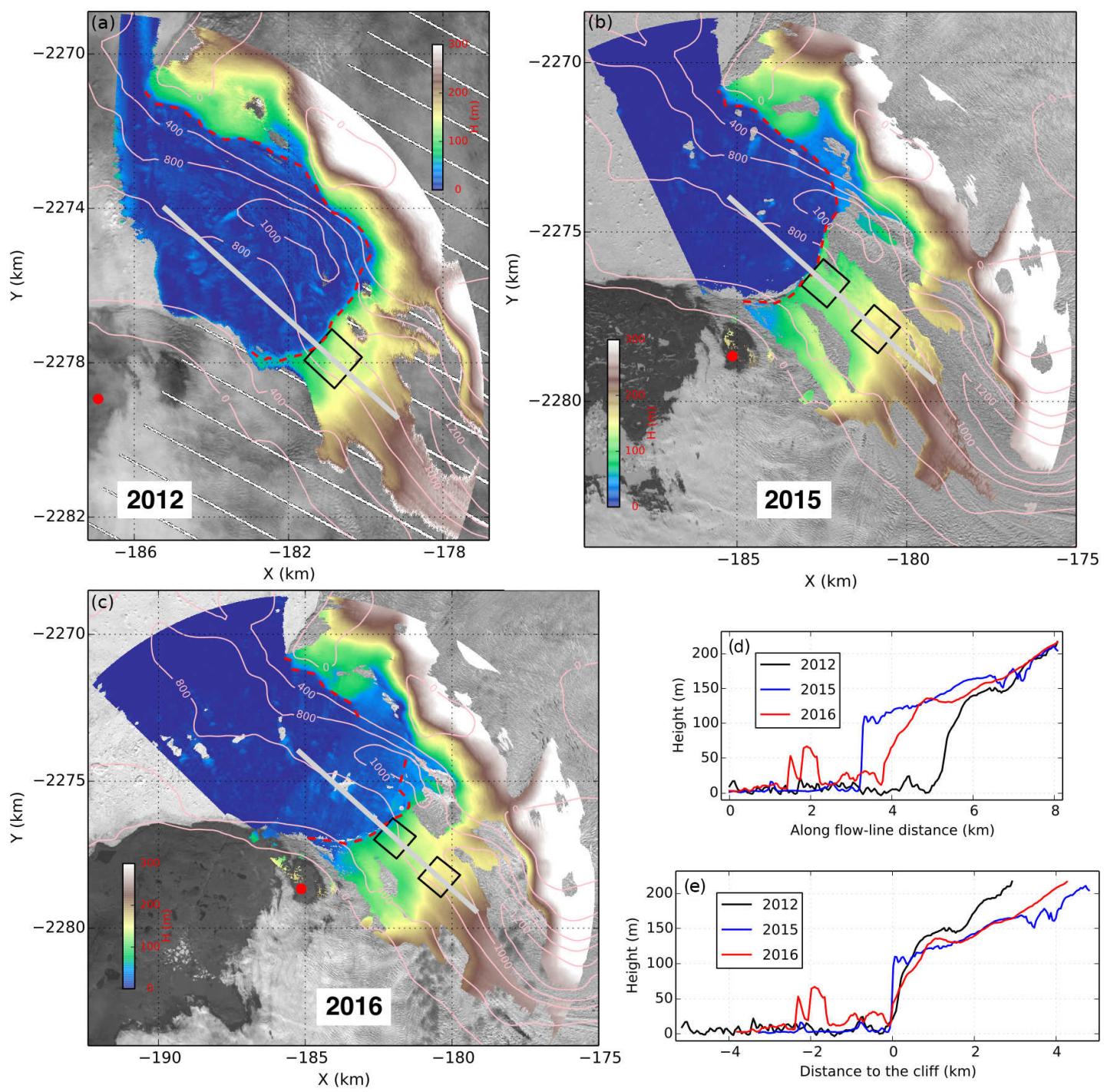

Figure 7. DEM for the glacier front, derived from median average of DEM estimates separated by 2 min during a 1-day period. For each subplot, red dot shows location of the radar, and pink contours show bed bathymetry in meters (An et al., 2017). Dashed red line shows the glacier front from TRI image. Note that in 2016 it was not possible to distinguish a portion of the glacier front from TRI measurements; hence it is not marked on the map. The background image for (a) was acquired on 6 August 2012 by Landsat-7; white stripes are data gaps. Background image in (b) was acquired on 4 June 2015 by Landsat-8. Background image in (c) was acquired on 13 June 2016 by Landsat8. Note that uncertainty increases with distance to the radar. Mean elevation of the black box $(1 \mathrm{~km} \times 1 \mathrm{~km}$ outlines in a-c) immediately adjacent to the glacier front is 99,109 , and $124 \mathrm{~m}$ for 2012, 2015, and 2016, respectively; we use this to represent the mean elevation within $1 \mathrm{~km}$ to the glacier front. Mean elevation of the black box upstream $(1 \mathrm{~km} \times 1 \mathrm{~km}$ outlines in $\mathbf{b}$ and $\mathbf{c}, 2-3 \mathrm{~km}$ to the glacier front $)$ is 154 and $158 \mathrm{~m}$ for 2015 and 2016, respectively. Black, blue, and red line in (d) show elevation profiles along a transect marked (grey lines in a-c). These transects have the same location in space. In (e), the distance of each transect is normalized so that the glacier fronts are in the same position.

water, so that ice motion could be driven by tidal current, or consider other sources of forcing. These forces are also likely to influence ice on the floating glacier tongue. At a point on the glacier where ice moves $\sim 90^{\circ}$ to radar LOS (Fig. $8 \mathrm{c}$ ), the TRI-derived velocity time series has a larger amplitude than the vertical tidal rate (Fig. 8d). This suggests that the floating ice near the calving front in 2015 is weak and moves in a manner similar to the mélange ice.

\section{Conclusions}

High spatial and temporal resolution measurements of the time-varying velocity field at the terminus of Jakobshavn Isbræ were acquired with terrestrial radar interferometry. Ocean tides modulate glacier velocity, and this modulation can be used to infer the location of grounding line. The phase relation between ice velocity and tidal rate suggests a $\sim 1 \mathrm{~km}$ 

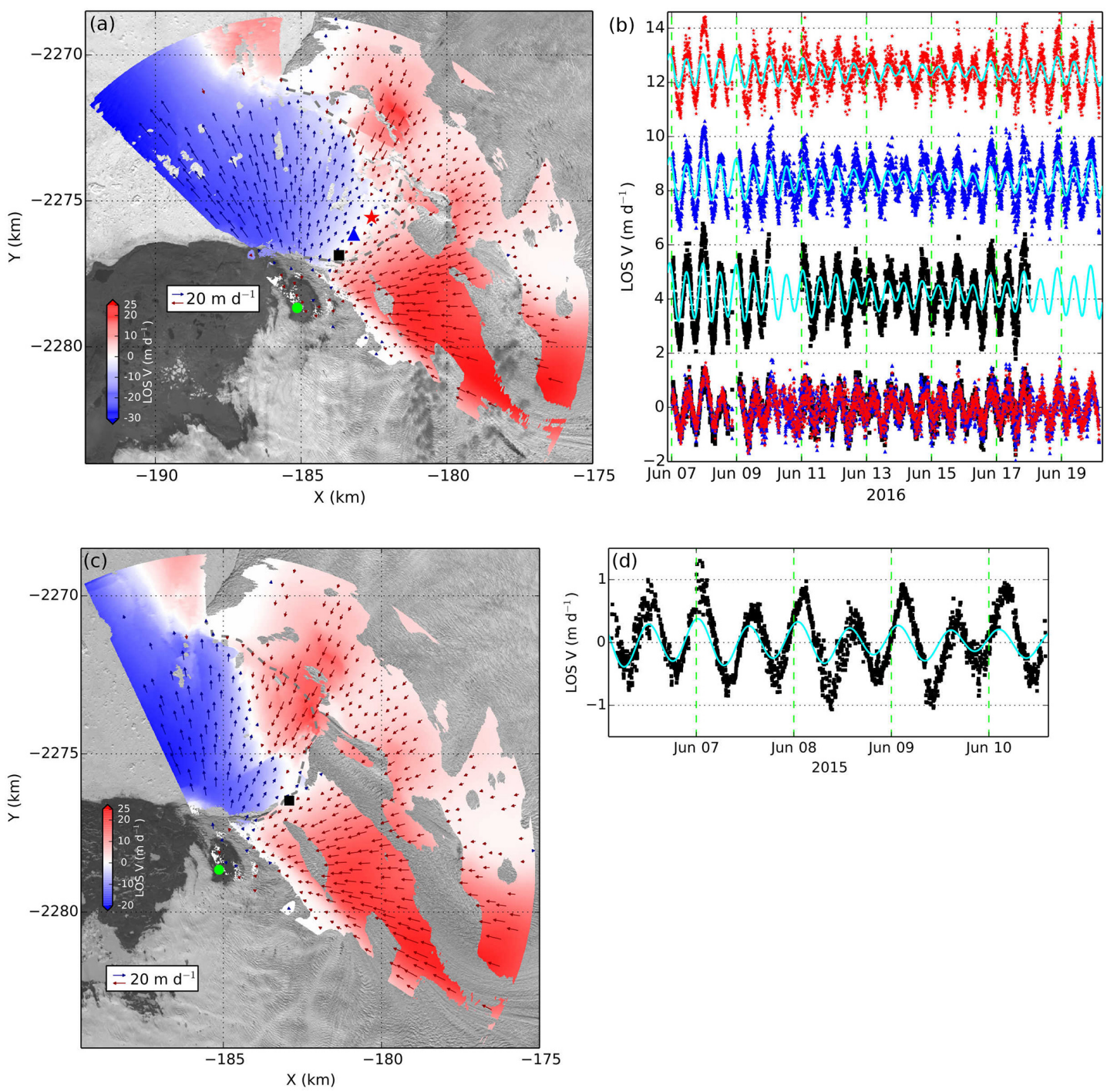

Figure 8. (a, b) TRI observed ice motion that is non-parallel to long-term ice flow motion in the mélange of 2016. In (a), color map shows LOS velocity by interferometry, from a 1-day median average. Arrows show velocity estimates from feature tracking projected onto the LOS direction (dark red when ice moves towards the radar and dark blue when ice moves away). Dashed grey line shows glacier front location from TRI image. Black square, blue triangle, and red star mark three points where 2-D velocity direction is nearly perpendicular to radar LOS. Their LOS velocity time series are shown in (b). Note that the point with blue triangle marker corresponds to the marked point in Fig. 3a. Top three rows in (b) show TRI-observed LOS velocities for selected points; cyan curves are predicted LOS velocities based on the imaging geometry, assuming ice is free-floating. LOS velocities are offset for clarity. Bottom row shows residual time series by subtracting the cyan curves. (c, d) TRI observed ice motion that is non-parallel to long-term ice flow motion on the glacier front for 2015. Colors and arrows in (c) represent the same parameters as in (a). A point immediately adjacent to the glacier front was chosen, marked by black square, with its LOS velocity observed with TRI and predicted by tide variations shown in (d). Cyan curve in (d) shows predicted LOS velocities.

wide floating zone in early summer of 2015 and 2016, where TRI-observed velocity variation contains ice up-and-down motion caused by tide rise and fall, and perhaps a component that is non-parallel to long-term ice flow motion due to tidal currents. The floating zone moves together with calved ice through most of the calving season. However, in late summer 2012, there is no evidence of a floating ice tongue. We hypothesize that Jakobshavn Isbræ maintains a short floating tongue from winter to early summer, when ice flow exceeds ice loss by calving and the glacier front advances. In summer, iceberg calving surpasses ice flow, and the glacier front retreats, becoming nearly grounded by late summer. TRIderived digital elevation models support this hypothesis: in early summer, there is a $\sim 1 \mathrm{~km}$ wide zone with relatively thin ice $(<110 \mathrm{~m})$ above local sea level; in late summer, ice thickness near the glacier front increases dramatically and buoyancy is insufficient to support a floating glacier front. 
Data availability. Landsat-7/8 and Sentinel-2 images were downloaded through the U.S. Department of the Interior U.S. Geological Survey (2018).

\section{The Supplement related to this article is available online at https://doi.org/10.5194/tc-12-1387-2018-supplement.}

Competing interests. The authors declare that they have no conflict of interest.

Acknowledgements. We acknowledge Denise Holland at the Center for Global Sea Level Change at New York University Abu Dhabi for organizing the field logistics for the 2015 and 2016 campaign. Judy McIlrath of the University of South Florida is thanked for help in the 2012 fieldwork. This research was partially supported by NASA grant NNX12AK29G to Timothy H. Dixon. David M. Holland acknowledges support from NYU Abu Dhabi grant G1204, NSF award ARC-1304137, and NASA Oceans Melting Greenland NNX15AD55G. Surui Xie thanks Nicholas Voss at the University of South Florida for helpful discussions. Comments from editor Olaf Eisen and two anonymous reviewers are greatly appreciated.

Edited by: Olaf Eisen

Reviewed by: two anonymous referees

\section{References}

Aðalgeirsdóttir, G., Smith, A. M., Murray, T., King, M. A., Makinson, K., Nicholls, K. W., and Behar, A. E.: Tidal influence on Rutford Ice Stream, West Antarctica: observations of surface flow and basal processes from closely spaced GPS and passive seismic stations, J. Glaciol., 54, 715-724, https://doi.org/10.3189/002214308786570872, 2008.

Amundson, J. M., Fahnestock, M., Truffer, M., Brown, J., Lüthi, M. P., and Motyka, R. J.: Ice mélange dynamics and implications for terminus stability, Jakobshavn Isbræ, Greenland, J. Geophys. Res., 115, F01005, https://doi.org/10.1029/2009JF001405, 2010.

An, L., Rignot, E., Elieff, S., Morlighem, M., Millan, R., Mouginot, J., Holland, D. M., Holland, D., and Paden, J.: Bed elevation of Jakobshavn Isbræ, West Greenland, from high-resolution airborne gravity and other data, Geophys. Res. Lett., 44, 37283736, https://doi.org/10.1002/2017GL073245, 2017.

Anandakrishnan, S. and Alley, R. B.: Tidal forcing of basal seismicity of ice stream C, West Antarctica, observed far inland, J. Geophys. Res., 102, 15183-15196, https://doi.org/10.1029/97JB01073, 1997.

Clarke, T. S. and Echelmeyer, K.: Seismic-reflection evidence for a deep subglacial trough beneath Jakobshavns Isbræ, West Greenland, J. Glaciol., 42, 219-232, https://doi.org/10.1017/S0022143000004081, 1996.

Davis, J. L., De Juan, J., Nettles, M., Elosegui, P., and Andersen, M. L.: Evidence for non-tidal diurnal velocity variations of Helheim Glacier, East Greenland, J. Glaciol., 60, 1169-1180, https://doi.org/10.3189/2014JoG13J230, 2014.

de Juan, J., Elósegui, P., Nettles, M., Larsen, T. B., Davis, J. L., Hamilton, G. S., Stearns, L. A., Andersen, M. L., Ekström, G., Ahlstrøm, A. P., and Stenseng, L.: Sudden increase in tidal response linked to calving and acceleration at a large Greenland outlet glacier, Geophys. Res. Lett., 37, L12501, https://doi.org/10.1029/2010GL043289, 2010.

Doake, C. S. M., Corr, H. F. J., Nicholls, K. W., Gaffikin, A., Jenkins, A., Bertiger, W. I., and King, M. A.: Tide-induced lateral movement of Brunt Ice Shelf, Antarctica, Geophys. Res. Lett., 29, 1226, https://doi.org/10.1029/2001GL014606, 2002.

Enderlin, E. M. and Howat, I. M.: Submarine melt rate estimates for floating termini of Greenland outlet glaciers (2000-2010), J. Glaciol., 59, 67-75, https://doi.org/10.3189/2013JoG12J049, 2013.

Gogineni, S., Yan, J. B., Paden, J., Leuschen, C., Li, J., RodriguezMorales, F., Braaten, D., Purdon, K., Wang, Z., Liu, W., and Gauch, J.: Bed topography of Jakobshavn Isbræ, Greenland, and Byrd Glacier, Antarctica, J. Glaciol., 60, 813-833, https://doi.org/10.3189/2014JoG14J129, 2014.

Heinert, M. and Riedel, B.: Parametric modelling of the geometrical ice-ocean interaction in the Ekstroemisen grounding zone based on short time-series, Geophys. J. Int., 169, 407-420, https://doi.org/10.1111/j.1365-246X.2007.03364.x, 2007.

Holland, D. M., Thomas, R. H., De Young, B., Ribergaard, M. H., and Lyberth, B.: Acceleration of Jakobshavn Isbræ triggered by warm subsurface ocean waters, Nat. Geosci., 1, 659-664, https://doi.org/10.1038/ngeo316, 2008.

Holland, D. M., Voytenko, D., Christianson, K., Dixon, T. H., Mel, M. J., Parizek, B. R., Vaňková, I., Walker, R. T., Walter, J. I., Nicholls, K., and Holland, D.: An Intensive Observation of Calving at Helheim Glacier, East Greenland, Oceanography, 29, 4661, https://doi.org/10.5670/oceanog.2016.98, 2016.

Howat, I. M., Ahn, Y., Joughin, I., van den Broeke, M. R., Lenaerts, J., and Smith, B.: Mass balance of Greenland's three largest outlet glaciers, 2000-2010, Geophys. Res. Lett., 38, L12501, https://doi.org/10.1029/2011GL047565, 2011.

Iglewicz, B. and Hoaglin, D. C.: How to detect and handle outliers, Vol. 16, Asq Press, 1993.

Joughin, I., Abdalati, W., and Fahnestock, M.: Large fluctuations in speed on Greenland's Jakobshavn Isbræ glacier, Nature, 432, 608-610, https://doi.org/10.1038/nature03130, 2004.

Joughin, I., Howat, I. M., Fahnestock, M., Smith, B., Krabill, W., Alley, R. B., Stern, H., and Truffer, M.: Continued evolution of Jakobshavn Isbræ following its rapid speedup, J. Geophys. Res., 113, F04006, https://doi.org/10.1029/2008JF001023, 2008.

Joughin, I., Smith, B., Shean, D., and Floricioiu, D.: Brief communication: Further summer speedup of Jakobshavn Isbræ, The Cryosphere, 8, 209-214, https://doi.org/10.5194/tc-8-209-2014, 2014.

Makinson, K., King, M. A., Nicholls, K. W., and Hilmar Gudmundsson, G.: Diurnal and semidiurnal tide-induced lateral movement of Ronne Ice Shelf, Antarctica, Geophys. Res. Lett., 39, L10501, https://doi.org/10.1029/2012GL051636, 2012.

Motyka, R. J., Truffer, M., Fahnestock, M., Mortensen, J., Rysgaard, S., and Howat, I.: Submarine melting of the 1985 Jakobshavn Isbræ floating tongue and the trigger- 
ing of the current retreat, J. Geophys. Res., 116, F01007, https://doi.org/10.1029/2009JF001632, 2011.

Myers, P. G. and Ribergaard, M. H.: Warming of the polar water layer in Disko Bay and potential impact on Jakobshavn Isbræ, J. Phys. Oceanogr., 43, 2629-2640, https://doi.org/10.1175/JPOD-12-051.1, 2013.

Peters, I. R., Amundson, J. M., Cassotto, R., Fahnestock, M., Darnell, K. N., Truffer, M., and Zhang, W. W.: Dynamic jamming of iceberg-choked fjords, Geophys. Res. Lett., 42, 1122-1129, https://doi.org/10.1002/2014GL062715, 2015.

Podrasky, D., Truffer, M., Fahnestock, M., Amundson, J. M., Cassotto, R., and Joughin, I.: Outlet glacier response to forcing over hourly to interannual timescales, Jakobshavn Isbræ, Greenland, J. Glaciol., 58, 1212-1226, https://doi.org/10.3189/2012JoG12J065, 2012.

Podrasky, D., Truffer, M., Lüthi, M., and Fahnestock, M.: Quantifying velocity response to ocean tides and calving near the terminus of Jakobshavn Isbræ, Greenland, J. Glaciol., 60, 609-621, https://doi.org/10.3189/2014JoG13J130, 2014.

Richter, A., Rysgaard, S., Dietrich, R., Mortensen, J., and Petersen, D.: Coastal tides in West Greenland derived from tide gauge records, Ocean Dynam., 61, 39-49, https://doi.org/10.1007/s10236-010-0341-z, 2011.

Rignot, E. and Kanagaratnam, P.: Changes in the velocity structure of the Greenland Ice Sheet, Science, 311, 986-990, https://doi.org/10.1126/science.1121381, 2006.

Rignot, E., Mouginot, J., and Scheuchl, B.: Antarctic grounding line mapping from differential satellite radar interferometry, Geophys. Res. Lett., 38, L10504, https://doi.org/10.1029/2011GL047109, 2011.

Rosenau, R., Schwalbe, E., Maas, H. G., Baessler, M., and Dietrich, R.: Grounding line migration and high-resolution calving dynamics of Jakobshavn Isbræ, West Greenland, J. Geophys. Res., 118, 382-395, https://doi.org/10.1029/2012JF002515, 2013.

Rosier, S. H. and Gudmundsson, G. H.: Tidal controls on the flow of ice streams, Geophys. Res. Lett., 43, 4433-4440, https://doi.org/10.1002/2016GL068220, 2016.

Schoof, C.: Ice sheet grounding line dynamics: Steady states, stability, and hysteresis, J. Geophys. Res., 112, https://doi.org/10.1029/2006JF000664, 2007.

Thomas, R. H.: Tide-induced perturbations of glacier velocities, Global Planet. Chang., 59, 217-224, https://doi.org/10.1016/j.gloplacha.2006.11.017, 2007.

Truffer, M. and Motyka, R. J.: Where glaciers meet water: Subaqueous melt and its relevance to glaciers in various settings, Rev. Geophys., 54, 220-239, https://doi.org/10.1002/2015RG000494, 2016.

U.S. Department of the Interior U.S. Geological Survey: USGS EarthExplorer: available at: https://earthexplorer.usgs.gov/, last access: 13 April, 2018.
Van Der Veen, C. J., Plummer, J. C., and Stearns, L. A.: Controls on the recent speed-up of Jakobshavn Isbræ, West Greenland, J. Glaciol., 57, 770-782, https://doi.org/10.3189/002214311797409776, 2011.

Vieli, A., Funk, M., and Blatter, H.: Flow dynamics of tidewater glaciers: a numerical modelling approach, J. Glaciol., 47, 595606, https://doi.org/10.3189/172756501781831747, 2001.

Voytenko, D., Stern, A., Holland, D. M., Dixon, T. H., Christianson, K., and Walker, R. T.: Tidally driven ice speed variation at Helheim Glacier, Greenland, observed with terrestrial radar interferometry, J. Glaciol., 61, 301-308, https://doi.org/10.3189/2015JoG14J173, 2015a.

Voytenko, D., Dixon, T. H., Howat, I. M., Gourmelen, N., Lembke, C., Werner, C. L., De La Peña, S., and Oddsson, B.: Multi-year observations of Breiðamerkurjökull, a marine-terminating glacier in southeastern Iceland, using terrestrial radar interferometry, J. Glaciol., 61, 42-54, https://doi.org/10.3189/2015JoG14J099, 2015b.

Voytenko, D., Dixon, T. H., Luther, M. E., Lembke, C., Howat, I. M., and de la Peña, S.: Observations of inertial currents in a lagoon in southeastern Iceland using terrestrial radar interferometry and automated iceberg tracking, Comput. Geosci., 82, 23-30, https://doi.org/10.1016/j.cageo.2015.05.012, 2015c.

Voytenko, D., Dixon, T. H., Holland, D. M., Cassotto, R., Howat, I. M., Fahnestock, M. A., Truffer, M., and de la Peña, S.: Acquisition of a $3 \mathrm{~min}$, two-dimensional glacier velocity field with terrestrial radar interferometry, J. Glaciol., 63, 629-636, https://doi.org/10.1017/jog.2017.28, 2017.

Walker, R. T., Parizek, B. R., Alley, R. B., Anandakrishnan, S., Riverman, K. L., and Christianson, K.: Ice-shelf tidal flexure and subglacial pressure variations, Earth Planet. Sc. Lett., 361, 422 428, https://doi.org/10.1016/j.epsl.2012.11.008, 2013.

Walters, R. A.: Small-amplitude, short-period variations in the speed of a tide-water glacier in southcentral Alaska, USA, Ann. Glaciol., 12, 187-191, https://doi.org/10.1017/S0260305500007175, 1989.

Werner, C., Strozzi, T., Wiesmann, A., and Wegmüller, U.: GAMMA's portable radar interferometer, in: Proc. 13th FIG Symp. Deform. Meas. Anal, 1-10, 2008.

Xie, S., Dixon, T. H., Voytenko, D., Holland, D. M., Holland, D., and Zheng, T.: Precursor motion to iceberg calving at Jakobshavn Isbræ, Greenland, observed with terrestrial radar interferometry, J. Glaciol., 62, 1134-1142, https://doi.org/10.1017/jog.2016.104, 2016. 